\title{
Regional Variation in Urinary Catheter Use and Catheter-Associated Urinary Tract Infection: Results from a National Collaborative
}

\author{
M. Todd Greene, PhD, MPH; $;^{1,2}$ Mohamad G. Fakih, MD, MPH; ${ }^{3}$ Karen E. Fowler, MPH; $;^{2,4}$ \\ Jennifer Meddings, MD, MS; ${ }^{1,2}$ David Ratz, MS; ${ }^{2,4}$ Nasia Safdar, MD; ${ }^{5}$ \\ Russell N. Olmsted, MPH; ${ }^{6}$ Sanjay Saint, MD, MPH ${ }^{1,2,4}$
} ов ЕстіVE. To examine regional variation in the use and appropriateness of indwelling urinary catheters and catheter-associated urinary
tract infection (CAUTI).

DESIGN AND SETTING. Cross-sectional study.

PARTICIPANTS. US acute care hospitals.

METHODS. Hospitals were divided into 4 regions according to the US Census Bureau. Baseline data on urinary catheter use, catheter appropriateness, and CAUTI were collected from participating units. The catheter utilization ratio was calculated by dividing the number of catheter-days by the number of patient-days. We used the National Healthcare Safety Network (NHSN) definition (number of CAUTIs per 1,000 catheter-days) and a population-based definition (number of CAUTIs per 10,000 patient-days) to calculate CAUTI rates. Logistic and Poisson regression models were used to assess regional differences.

RESULTS. Data on 434,207 catheter-days over 1,400,770 patient-days were collected from 1,101 units within 726 hospitals across 34 states. Overall catheter utilization was $31 \%$. Catheter utilization was significantly higher in non-intensive care units (ICUs) in the West compared with non-ICUs in all other regions. Approximately 30\%-40\% of catheters in non-ICUs were placed without an appropriate indication. Catheter appropriateness was the lowest in the West. A total of 1,099 CAUTIs were observed (NHSN rate of 2.5 per 1,000 catheter-days and a population-based rate of 7.8 per 10,000 patient-days). The population-based CAUTI rate was highest in the West (8.9 CAUTIs per 10,000 patient-days) and was significantly higher compared with the Midwest, even after adjusting for hospital characteristics $(P=.02)$.

CONCLUSIONs. Regional differences in catheter use, appropriateness, and CAUTI rates were detected across US hospitals.

Infect Control Hosp Epidemiol 2014;35(S3):S99-S106

Catheter-associated urinary tract infection (CAUTI) accounts for approximately one-third of all healthcare-associated infections in the United States ${ }^{1}$ and leads to excess morbidity, mortality and costs. ${ }^{2,3}$ The urinary catheter is also associated with other patient safety problems, such as trauma, ${ }^{4}$ increased patient discomfort, ${ }^{5}$ and immobility. ${ }^{6}$ CAUTI prevention has important cost implications for hospitals, particularly since the Centers for Medicare and Medicaid Services (CMS) has classified hospital-acquired CAUTI as reasonably preventable and no longer reimburses hospitals for this condition. Among the most effective approaches for reducing CAUTI is restricting use of indwelling urethral catheters for a list of appropriate indications, ${ }^{8}$ because a substantial proportion of inpatients have catheters placed at some point during their hospitalization, with many of these insertions not considered medically necessary. ${ }^{9,10}$ The Centers for Disease Control and Prevention (CDC) has issued guidelines detailing high-priority recommendations for implementing CAUTI prevention. Inserting catheters only for appropriate indications and leaving in place only for as long as medically necessary is 1 of the strong (category IB) recommendations. ${ }^{8}$ Previous studies have shown that targeted implementation of recommendations from existing guidelines can lead to reduced overall catheter utilization and increased appropriate utilization. ${ }^{11-17}$ Despite the presence of evidence-based guidelines, previous work has shown that the use of evidence-based CAUTI prevention practices vary nationally. ${ }^{18-20}$

Variability in the use of medical devices and device-related infections by patient characteristics, hospital care locations, and hospital characteristics has been well documented na-

Affliations: 1. Department of Internal Medicine, University of Michigan Medical School, Ann Arbor, Michigan; 2. Veterans Affairs/University of Michigan Patient Safety Enhancement Program, Ann Arbor, Michigan; 3. St. John Hospital and Medical Center, Detroit, Michigan; 4. Hospital Outcomes Program of Excellence, Veterans Affairs Ann Arbor Healthcare System, Ann Arbor, Michigan; 5. William S. Middieton Memorial Veterans Hospital, Madison, Wisconsin; and Department of Medicine, University of Wisconsin School of Medicine and Public Health, Madison, Wisconsin; 6. Saint Joseph Mercy Health System, Ann Arbor, Michigan.

Received April 11, 2014; accepted April 27, 2014; electronically published September 15, 2014.

(C) 2014 by The Society for Healthcare Epidemiology of America. All rights reserved. 0899-823X/2014/35S3-0015\$15.00. DOI: 10.1086/677825 
tionally. ${ }^{10}$ Urinary catheter use and, subsequently, CAUTI rates are generally higher in critical care areas compared with inpatient medical wards; however, the proportional distribution of all CAUTI among hospitalized patients is higher outside of the intensive care unit (ICU). ${ }^{10,21,22}$ While prior studies have also demonstrated regional variation in the use of urinary catheters after accounting for patient-level characteristics, these studies have been limited to claims data from older surgical populations ${ }^{23-25}$ and patients residing in longterm care facilities. ${ }^{26}$

Starting in August 2011, the Health Research and Educational Trust of the American Hospital Association and its academic partners have led On the CUSP: Stop CAUTI, an Agency for Healthcare Research and Quality-funded national initiative to reduce CAUTI in acute care hospitals. The organizational structure and key components of this national initiative have been described previously. ${ }^{27}$ Using baseline data collected as part of this national initiative, we sought to explore nationwide variation in the use of these medical devices and CAUTI across a diverse set of units within acute care hospitals across the United States. Additionally, we examined the extent to which the appropriateness of urinary catheterization varies regionally.

\section{METHODS}

\section{Data Collection}

For this analysis, we used baseline data collected from the first 5 cohorts of hospitals participating in the On the CUSP: Stop CAUTI initiative. Planning, recruitment, and data collection for additional cohorts are ongoing. Participating hospital units were required to report both clinical process and infection outcome data during the 3 main phases of the initiative: baseline, implementation, and sustainability. The number of patient-days and process data on urinary catheter use and appropriateness of catheter use (urinary catheterdays with an appropriate indication divided by all urinary catheter-days during the same period) was collected during three 5-day weeks ( 15 days) during the 3 -month baseline period. The catheter utilization ratio was calculated by dividing the number of catheter-days by the number of patientdays. Indications for urinary catheter use were classified as appropriate or inappropriate on the basis of the 2009 Healthcare Infection Control Practices Advisory Committee guidelines published by the CDC. ${ }^{8}$ The number of CAUTI events within participating units was collected by infection preventionists during the baseline period. We used the conventional CDC National Healthcare Safety Network (NHSN) definition (number of symptomatic CAUTIs fitting the NHSN definition per number of catheter-days during the same period $x$ 1,000 ) and an alternative population-based definition (number of symptomatic CAUTIs fitting the NHSN definition per number of patient-days during the same period $\times 10,000$ ) to calculate CAUTI rates. The population-based CAUTI rate may provide a better assessment for infection prevention ef- forts focused on reducing inappropriate urinary catheter use. ${ }^{28}$ Hospital characteristics were acquired from the 2010 American Hospital Association Annual Survey Database. All investigated process and outcome data were aggregate baseline values from each participating unit.

\section{Statistical Analysis}

Descriptive statistics were utilized to explore the hospital characteristics, process, and outcome data across geographical regions. The hospitals were divided into 4 regions--Northeast, Midwest, South, and West-according to the US Census Bureau regional breakdowns. ${ }^{29}$ Logistic regression and Poisson regression models were used to test for differences in the

TABLE 1. Participating Hospitals and Units by Geographic Location

\begin{tabular}{|c|c|c|c|c|}
\hline Location & Hospitals & Units & $\mathrm{ICU}$ & Non-ICL \\
\hline \multicolumn{5}{|l|}{ Northeast } \\
\hline Connecticut & 9 & 9 & 3 & 6 \\
\hline Massachusetts & 14 & 17 & 5 & 12 \\
\hline New Jersey & 35 & 63 & 31 & 32 \\
\hline Pennsylvania & 9 & 12 & 5 & 7 \\
\hline \multicolumn{5}{|l|}{ Midwest } \\
\hline Illinois & 43 & 55 & 23 & 32 \\
\hline Indiana & 31 & 47 & 18 & 29 \\
\hline Michigan & 40 & 63 & 41 & 22 \\
\hline Wisconsin & 14 & 17 & 4 & 13 \\
\hline Kansas & 70 & 84 & 8 & 76 \\
\hline Missouri & 46 & 69 & 26 & 43 \\
\hline Nebraska & 9 & 9 & 1 & 8 \\
\hline North Dakota & 8 & 9 & 1 & 8 \\
\hline South Dakota & 3 & 3 & 0 & 3 \\
\hline \multicolumn{5}{|l|}{ South } \\
\hline Florida & 29 & 62 & 47 & 15 \\
\hline Georgia & 27 & 37 & 20 & 17 \\
\hline Maryland & 35 & 67 & 23 & 44 \\
\hline South Carolina & 18 & 27 & 9 & 18 \\
\hline West Virginia & 11 & 11 & 5 & 6 \\
\hline Alabama & 31 & 40 & 13 & 27 \\
\hline Kentucky & 20 & 27 & 12 & 15 \\
\hline Mississippi & 4 & 4 & 0 & 4 \\
\hline Arkansas & 36 & 76 & 29 & 47 \\
\hline Louisiana & 34 & 48 & 14 & 34 \\
\hline Oklahoma & 19 & 25 & 13 & 12 \\
\hline Texas & 7 & 9 & 1 & 8 \\
\hline \multicolumn{5}{|l|}{ West } \\
\hline Arizona & 10 & 16 & 10 & 6 \\
\hline Colorado & 14 & 16 & 4 & 12 \\
\hline Nevada & 18 & 27 & 11 & 16 \\
\hline Utah & 12 & 17 & 10 & 7 \\
\hline Alaska & 3 & 5 & 3 & 2 \\
\hline California & 14 & 31 & 8 & 23 \\
\hline Hawaii & 15 & 29 & 9 & 20 \\
\hline Oregon & 12 & 25 & 6 & 19 \\
\hline Washington & 26 & 45 & 30 & 15 \\
\hline Total & 726 & 1,101 & 443 & 658 \\
\hline
\end{tabular}

NOTE. ICU, intensive care unit. 
TA BLE 2. Urinary Catheter Utilization and Catheter-Associated Urinary Tract Infection (CAUTI) Rates by Unit Type and Geographic Region

\begin{tabular}{|c|c|c|c|c|c|c|}
\hline Region & CAUTIs & Device-days & Patient-days & $\begin{array}{c}\text { Catheter utilization } \\
\text { ratio }\end{array}$ & $\begin{array}{l}\text { NHSN } \\
\text { rate }\end{array}$ & $\begin{array}{l}\text { Population } \\
\text { rate }\end{array}$ \\
\hline \multicolumn{7}{|l|}{$\mathrm{ICU}$} \\
\hline Northeast & 56 & 23,885 & 38,740 & 0.617 & 2.3 & 14.5 \\
\hline Midwest & 106 & 49,800 & 80,736 & 0.617 & 2.1 & 13.1 \\
\hline South & 277 & 106,004 & 167,087 & 0.634 & 2.6 & 16.6 \\
\hline West & 127 & 50,566 & 93,503 & 0.541 & 2.5 & 13.6 \\
\hline Total & 566 & 230,255 & 380,066 & 0.606 & 2.5 & 14.9 \\
\hline \multicolumn{7}{|l|}{ Non-ICU } \\
\hline Northeast & 77 & 22,112 & 126,391 & 0.175 & 3.5 & 6.1 \\
\hline Midwest & 137 & 59,028 & 301,531 & 0.196 & 2.3 & 4.5 \\
\hline South & 176 & 72,431 & 383,359 & 0.189 & 2.4 & 4.6 \\
\hline West & 143 & 50,381 & 209,423 & 0.241 & 2.8 & 6.8 \\
\hline Total & 533 & 203,952 & $1,020,704$ & 0.200 & 2.6 & 5.2 \\
\hline \multicolumn{7}{|l|}{ All units } \\
\hline Northeast & 133 & 45,997 & 165,131 & 0.279 & 2.9 & 8.1 \\
\hline Midwest & 243 & 108,828 & 382,267 & 0.285 & 2.2 & 6.4 \\
\hline South & 453 & 178,435 & 550,446 & 0.324 & 2.5 & 8.2 \\
\hline West & 270 & 100,947 & 302,926 & 0.333 & 2.7 & 8.9 \\
\hline Total & 1,099 & 434,207 & $1,400,770$ & 0.310 & 2.5 & 7.8 \\
\hline
\end{tabular}

NOTE. National Healthcare Safety Network (NHSN) rate was calculated as the number of symptomatic CAUTIs per 1,000 catheter-days. Population CAUTI rate was calculated as the number of symptomatic CAUTIs per 10,000 patient-days. ICU, intensive care unit.

process and outcome data across regions. Multivariable models were fit to account for the following characteristics: hospital bed size, hospital teaching affiliation, rural hospital location, critical access hospital, and ICU or floor unit. Scaling based on the deviances was used to adjust the standard errors in all regressions for the presence of overdispersion in the data. All analyses were at the hospital unit level and were performed using SAS (ver. 9.3; SAS Institute). The study was reviewed by the University of Michigan Institutional Review Board and received a determination of not regulated, since the analysis was at the hospital unit level and did not include identifiable patient-level data.

\section{RES ULTS}

\section{Characteristics of Recruited Units}

The number of participating hospitals and units by state and region are displayed in Table 1. Data were collected from 443 ICU and 658 non-ICU units in 726 hospitals across 34 states. The Northeast region consisted of 101 units (67 hospitals) from 4 states, the Midwest region consisted of 356 units (264 hospitals) from 9 states, the South region consisted of 433 units (271 hospitals) from 12 states, and the West region consisted of 211 units (124 hospitals) from 9 states. The percentage of teaching hospitals in the West was significantly higher than in the Midwest (50\% vs 35\%; $P=.002$ ) and South $(50 \%$ vs $34 \% ; P<.001)$. The Midwest had the highest percentages of rural $(49 \%$; $P<.001$ compared with all other regions) and critical access hospitals $(28 \% ; P<.001$ compared with all other regions). The percentage of participating units that were ICUs in the Midwest was significantly lower compared with the South (34\% vs $43 \% ; P=0.01)$ and the West (34\% vs $43 \% ; P=.04$ ).

\section{Urinary Catheter Use and Appropriateness}

Urinary catheter utilization by region and ICU status is summarized in Table 2. Across all participating units, catheter utilization was $31 \%$. As expected, utilization in the ICU (61\%) was greater than in the non-ICU $(20 \%)$. The West had the highest utilization in the non-ICU setting $(24 \%)$, while the South had the highest utilization in the ICU (63\%). Regional differences in catheter utilization adjusted for hospital characteristics are shown in Table 3. Compared with non-ICUs in the West, catheter utilization was significantly lower in non-ICUs in the Northeast $(P=.001)$ and South $(P=.007)$. Compared with ICUs in the West, catheter utilization was significantly higher in ICUs in all other regions (Northeast, $P=.02$; Midwest, $P=.002$; South, $P<.001$ ). Overall utilization did not vary by region after adjusting for hospital characteristics.

While the South had the highest percent of appropriate catheter placement in the ICU $(98 \%)$, all regions indicated catheters were placed appropriately at least $94 \%$ of the time in the ICU setting. The West had the lowest percent of appropriate catheter placement in the non-ICU setting (61\%). Regional differences in catheter appropriateness adjusted for hospital characteristics are shown in Table 3. Catheter appropriateness within the ICU setting was significantly higher in the South compared with the West $(P<.001)$. Catheter 
TA в LE 3. Multivariable Regression Estimates for Urinary Catheter Utilization and Appropriateness by Unit Type and Geographic Region

\begin{tabular}{|c|c|c|c|c|c|c|}
\hline \multirow[b]{2}{*}{ Region } & \multicolumn{3}{|c|}{ Catheter utilization ratio } & \multicolumn{3}{|c|}{ Catheter appropriateness } \\
\hline & ICU & Non-ICU & All units & $\mathrm{ICU}$ & Non-ICU & All units \\
\hline West & Reference & Reference & Reference & Reference & Reference & Reference \\
\hline Northeast & $1.16(1.03-1.30)$ & $0.76(0.65-0.90)$ & $0.95(0.85-1.05)$ & $1.17(0.69-1.99)$ & $1.52(1.06-2.17)$ & $1.43(1.07-1.92)$ \\
\hline Midwest & $1.17(1.06-1.29)$ & $0.89(0.78-1.01)$ & $1.03(0.94-1.12)$ & $1.50(0.94-2.41)$ & $1.46(1.11-1.93)$ & $1.48(1.17-1.87)$ \\
\hline South & $1.20(1.10-1.31)$ & $0.84(0.74-0.95)$ & $1.02(0.94-1.10)$ & $2.80(1.77-4.45)$ & $1.41(1.08-1.84)$ & $1.57(1.26-1.97)$ \\
\hline
\end{tabular}

NOTE. Regional estimates are adjusted for hospital bed size, teaching hospital status, rural hospital location, and critical access hospital status. The estimates for the all units column are also adjusted for intensive care unit (ICU) status. The estimates for catheter utilization were derived from Poisson regression models and reflect incidence rate ratios ( $95 \%$ confidence intervals $[\mathrm{CIs}])$. The estimates for catheter appropriateness were derived from logistic regression models and reflect odds ratios (95\% CIs). All models are based on the 1,046 (95.0\%) units with hospital characteristic data available from the 2010 American Hospital Association Annual Survey Database.

appropriateness in non-ICUs in the West was significantly lower than appropriateness in non-ICUs in all other regions (Northeast, $P=.02$; Midwest, $P=.007$; South, $P=.01$ ). Compared with the West, overall appropriateness was significantly higher in all other regions (Northeast, $P=.02$; Midwest, $P=.001$; South, $P<.001$ ) after adjusting for hospital characteristics.

Table 4 lists the specific catheter indications used in participating units by region. Use of the various indications did not differ substantially by region within the ICU setting. Notable findings regarding inappropriate indication use within the non-ICU setting were as follows: the West had the highest percentage of use of accurate measurement of urinary output in the critically ill patients, incontinence without a sacral or perineal pressure sore, and prolonged postoperative use; the South had the highest use of urine output monitoring outside of the ICU; and the Midwest had the highest use of other indications, which included transfer from the ICU, morbid obesity, immobility, dementia, and patient request. The use of accurate measurement of urinary output in the critically ill patients and prolonged postoperative use was significantly higher in the West compared with all other regions even after adjustment for hospital specific characteristics (results not shown).

\section{CAUTI Rates}

The number of patient-days, catheter-days, CAUTIs, and CAUTI rates by region and unit type are displayed in Table 2. The overall NHSN rate was 2.5 per 1,000 catheter-days and did not differ by unit type. The overall population-based rate was 7.8 per 10,000 patient-days and was higher in the ICU (14.9 per 10,000 patient-days) compared with the nonICU (5.2 per 10,000 patient-days). Across all participating units, the Northeast had the highest NHSN rate (2.9 per 1,000 catheter-days), and the West had the highest populationbased rate ( 8.9 per 10,000 patient-days). All regions had much higher population-based rates in the ICU compared with the non-ICU as expected, given higher catheter utilization rates and lower patient-days contributing to the denominator in the ICU. Conversely, NHSN rates within each region were lower in the ICU compared with the non-ICU, with the exception of the South. The South had the highest CAUTI rates in the ICU setting (NHSN rate, 2.6 per 1,000 catheter-days; population-based rate, 16.6 per 10,000 patient-days). In the non-ICU setting, the Northeast had the highest NHSN rate (3.5 per 1,000 catheter-days), and the West had the highest population-based rate (6.8 per 10,000 patient-days).

Regional differences in CAUTI rates adjusted for hospital characteristics are shown in Table 5. Compared with nonICUs in the West, non-ICUs in the Midwest had lower NHSN $(P=.03)$ and population-based $(P=.005)$ rates. Similarly, compared with all units in the West, units in the Midwest had lower NHSN $(P=.007)$ and population-based $(P=$ .02) rates. CAUTI in the ICU did not differ across regions after adjusting for hospital characteristics.

\section{DISCUSSION}

Several important findings emerged from our national study. We found that catheter utilization remains common across the United States, with 20\% in non-ICU settings and $61 \%$ in the ICU. Although catheter appropriateness in the ICU was uniformly high across all regions, we found that $30 \%$ $40 \%$ of catheters in the non-ICU setting may be placed without an appropriate indication. Overall urinary catheter utilization was highest in the West region, which was predominantly driven by higher utilization in the non-ICU setting. Coinciding with this, we found that the population-based CAUTI rate was also highest in the West. This finding may be driven in part by both fewer numbers of annual discharges and a slightly lower average length of stay in the West (4.4 days) compared with the national average ( 4.8 days).$^{30}$ We have previously illustrated that the NHSN rate may underestimate the burden of CAUTI and that the population-based rate may yield better estimates, particularly in settings where catheter utilization is high. ${ }^{28}$ In addition to having higher catheter utilization rates, inappropriate catheter use was also higher in the West compared with the other regions. We found 
TABLE 4. Urinary Catheter Indication Use by Unit Type and Geographic Region

\begin{tabular}{|c|c|c|c|c|c|}
\hline Indication & Northeast & Midwest & South & West & Total \\
\hline \multicolumn{6}{|l|}{$\mathrm{ICU}$} \\
\hline 1 & 3.2 & 2.7 & 3.2 & 3.2 & 3.1 \\
\hline 2 & 3.6 & 3.4 & 5.3 & 5.8 & 4.7 \\
\hline 3 & 1.7 & 1.7 & 1.9 & 2.4 & 1.9 \\
\hline 4 & 1.3 & 1.0 & 1.3 & 1.6 & 1.2 \\
\hline 5 & 4.4 & 4.0 & 4.5 & 4.6 & 4.4 \\
\hline 6 & 2.0 & 2.4 & 1.7 & 1.0 & 1.8 \\
\hline 7 & 84.1 & 80.8 & 83.0 & 82.5 & 82.5 \\
\hline 8 & 0.1 & 0.4 & 0.7 & 0.0 & 0.5 \\
\hline 9 & 0.3 & 0.5 & 0.3 & 0.9 & 0.4 \\
\hline 10 & 0.2 & 0.4 & 0.6 & 0.7 & 0.5 \\
\hline 11 & 3.1 & 2.9 & 1.7 & 3.6 & 2.4 \\
\hline 12 & 1.9 & 5.1 & 6.1 & 1.9 & 4.9 \\
\hline \multicolumn{6}{|l|}{ Non-ICU } \\
\hline 1 & 21.9 & 20.5 & 19.0 & 12.1 & 18.4 \\
\hline 2 & 8.8 & 17.0 & 12.5 & 9.9 & 12.9 \\
\hline 3 & 16.6 & 7.2 & 13.3 & 20.8 & 13.4 \\
\hline 4 & 3.8 & 5.6 & 5.0 & 2.8 & 4.6 \\
\hline 5 & 3.8 & 8.7 & 9.2 & 6.7 & 8.0 \\
\hline 6 & 10.1 & 10.5 & 7.9 & 6.8 & 8.7 \\
\hline 7 & 15.1 & 11.2 & 12.7 & 21.0 & 14.1 \\
\hline 8 & 9.8 & 10.2 & 11.8 & 11.1 & 11.0 \\
\hline 9 & 1.4 & 1.6 & 1.9 & 2.2 & 1.8 \\
\hline 10 & 0.5 & 1.1 & 1.4 & 2.8 & 1.5 \\
\hline 11 & 4.8 & 8.7 & 8.0 & 7.3 & 7.7 \\
\hline 12 & 7.1 & 4.4 & 5.0 & 5.3 & 5.1 \\
\hline \multicolumn{6}{|l|}{ All units } \\
\hline 1 & 11.1 & 11.3 & 9.7 & 8.8 & 10.2 \\
\hline 2 & 5.8 & 10.0 & 8.2 & 8.3 & 8.5 \\
\hline 3 & 8.0 & 4.4 & 6.6 & 13.9 & 7.2 \\
\hline 4 & 2.3 & 3.2 & 2.8 & 2.4 & 2.8 \\
\hline 5 & 4.1 & 6.3 & 6.4 & 5.9 & 6.0 \\
\hline 6 & 5.5 & 6.3 & 4.3 & 4.6 & 5.0 \\
\hline 7 & 55.0 & 46.9 & 54.2 & 43.9 & 50.8 \\
\hline 8 & 4.2 & 5.2 & 5.3 & 7.0 & 5.4 \\
\hline 9 & 0.8 & 1.1 & 1.0 & 1.7 & 1.1 \\
\hline 10 & 0.3 & 0.7 & 0.9 & 2.0 & 1.0 \\
\hline 11 & 3.8 & 5.8 & 4.3 & 5.9 & 4.9 \\
\hline 12 & 4.1 & 4.7 & 5.6 & 4.0 & 5.0 \\
\hline
\end{tabular}

NOTE. Data are percentages. Columns within region and unit type do not add to $100 \%$ because some catheterizations $(\sim 7 \%)$ had more than 1 indication noted. The following indications are considered appropriate per recommended guidelines or given hospitalapproved indication: 1 , acute urinary retention or obstruction; 2 , perioperative use in selected surgeries; 3 , assist healing of perineal and sacral wounds in incontinent patients; 4, hospice/comfort/ paliative care; 5 , required immobilization for trauma or surgery; 6, chronic indwelling urinary catheter on admission; 7, accurate measurement of urinary output in the critically ill in the intensive care unit (ICU); 12, hospital approved indication (exclusive of any other inappropriate reasons). The following indications are considered inappropriate per recommended guidelines: 7 , accurate measurement of urinary output in the critically ill outside of the ICU; 8 , urine output monitoring outside of the ICU; 9, incontinence without a sacral or perineal pressure sore; 10 , prolonged postoperative use; 11, other, including transferred from the ICU, morbid obesity, immobility, confusion or dementia, and patient requests. that this disparity was largely driven by more frequent use of the indication of accurate measurement of urinary output in the critically ill patients in the non-ICU setting. In a sensitivity analysis in which we considered this particular indication as appropriate, significant regional differences in catheter appropriateness in non-ICU settings were no longer evident.

The regional variation in catheter utilization detected in our study is consistent with prior work. In a retrospective cohort analysis of postoperative patients, Wald et $\mathrm{a}^{2.3}$ reported that the West region was associated with a higher likelihood of having an indwelling urinary catheter at hospital discharge after hip fracture. Similarly, in a retrospective cohort analysis of older patients discharged to skilled nursing facilities following major cardiac, vascular, orthopedic, or gastrointestinal surgery, hospitalization in the Northeast and South regions was associated with lower likelihoods of extended catheterization compared with hospitalization in the West region. ${ }^{25}$ It has been previously suggested that this regional variation is possibly "attributed to patient demographic characteristics, regional practice styles, local regulations, and the availability of technologies and facilities."24(p121) In addition, practice patterns in the West may be impacted by different factors, including the penetrance of managed care and shorter length of stay. A recent retrospective analysis of the National Hospital Discharge Surveys from 2001 to 2010 has shown that the South has the highest proportion of catheterized hospitalized patients and was significantly associated with increased CAUTI risk even after adjusting for patient demographic and hospital-level characteristics. ${ }^{31}$ Across all units in our study, we found that catheter utilization in the South was comparable to the highest utilization found in the West. Furthermore, catheter utilization and the population CAUTI rate in the ICU were highest in the South.

Among a separate national cohort of hospitals participating in the NHSN, catheter utilization rates were approximately $62 \%$ in medical-surgical ICUs and $18 \%$ in non-ICU medicalsurgical wards. ${ }^{10}$ We found comparable catheter utilization rates in our study, with slightly higher utilization in non-ICU locations. NHSN CAUTI rates among the NHSN participating facilities were approximately 1.7 in medical-surgical ICUs and 1.4 in non-ICU medical-surgical wards. ${ }^{10}$ We found higher CAUTI rates in our study, with NHSN CAUTI rates of approximately 2.5 in both ICU and non-ICU locations. The CAUTI rates reported in our study reflect baseline values prior to units implementing CAUTI reduction steps as part of the On the CUSP: Stop CAUTI initiative. It is quite plausible that the higher rates of catheter utilization and CAUTI detected in our study - particularly in the non-ICU settingare driven in part by a substantial proportion of hospitals self-selecting units to participate in the On the CUSP: Stop CAUTI initiative on the basis of high catheter utilization and/ or CAUTI rates. Additionally, a greater percentage of the hospitals in our study were larger teaching facilities compared with those participating in the NHSN in general $(43 \%$ with 
TAвLE 5. Multivariable Regression Estimates for Catheter-Associated Urinary Tract Infection (CAUTI) Rates by Unit Type and Geographic Region

\begin{tabular}{|c|c|c|c|c|c|c|}
\hline & \multicolumn{3}{|c|}{ NHSN rate } & \multicolumn{3}{|c|}{ Population rate } \\
\hline & ICU & Non-ICU & All units & $\mathrm{ICU}$ & Non-ICU & All units \\
\hline West & Reference & Reference & Reference & Reference & Reference & Reference \\
\hline Northeast & $0.95(0.62-1.44)$ & $1.26(0.89-1.78)$ & $1.07(0.81-1.40)$ & $0.99(0.64-1.53)$ & $0.95(0.65-1.38)$ & $1.00(0.75-1.33)$ \\
\hline Midwest & $0.77(0.54-1.10)$ & $0.71(0.52-0.97)$ & $0.73(0.58-0.92)$ & $0.81(0.56-1.17)$ & $0.62(0.45-0.87)$ & $0.73(0.57-0.94)$ \\
\hline South & $0.98(0.73-1.31)$ & $0.80(0.60-1.07)$ & $0.89(0.73-1.09)$ & $1.05(0.78-1.42)$ & $0.68(0.50-0.93)$ & $0.89(0.72-1.11)$ \\
\hline
\end{tabular}

NOTE. National Healthcare Safety Network (NHSN) rate was calculated as the number of symptomatic CAUTIs per 1,000 catheter-days. Population rate was calculated as the number of symptomatic CAUTIs per 10,000 catheter-days. Regional estimates are adjusted for hospital bed size, teaching hospital status, rural hospital location, and critical access hospital status. The estimates for the all units column are also adjusted for intensive care unit (ICU) status. The estimates presented for both the NHSN and the population rates were derived from Poisson regression models and reflect incidence rate ratios ( $95 \%$ confidence intervals). All models are based on the 1,046 (95.0\%) units with hospital characteristic data available from the 2010 American Hospital Association Annual Survey Database.

bed size 200 or more and $38 \%$ teaching vs $25 \%$ and $11 \%$, respectively, among NHSN participating facilities). Prior work has suggested that larger teaching hospitals, which typically care for more medically complex patients, have a higher incidence of CAUTI and may be less likely to adopt CAUTI prevention policies. $^{32}$

Compared with recent data submitted by NHSN participating hospitals, we found greater differences in catheter utilization and CAUTI within non-ICU settings. Although the reporting of CAUTI in adult and pediatric ICUs to the NHSN has been mandated by the CMS since January $1,2012,{ }^{33}$ reporting in non-ICU locations is not yet required. As such, currently available CAUTI measures reported to the NHSN from non-ICU settings may not accurately reflect catheter utilization and the burden of CAUTI outside of the ICU. In August 2013, the CMS issued rules for quality reporting for the government fiscal year 2014 (October 1, 2013, to September 30, 2014). Among the proposed changes, starting January 1,2015 , CAUTI reporting will also be required by adult and pediatric medical, surgical, and medical-surgical wards. ${ }^{34}$

Our study should be interpreted in the context of several limitations. First, all of the process and outcome measures that we examined were aggregate data at the hospital unit level. As such, we were not able to account for patient-level factors that likely influence both the decision to place a catheter and the risk of CAUTI. Second, participation in the On the CUSP: Stop CAUTI initiative is voluntary. It is possible that certain units recruited may be high-performing units while others have elected to participate because of a recognized need for improvement. Furthermore, participating hospitals are given the liberty of choosing which unit(s) to implement the initiative in. While these issues may have caused potential selection bias, we have no reason to believe that they would be systematically different across the regions examined. Third, there are a variable number of units across the regions examined. Additionally, the hospitals and units that have elected to participate within a given region may not be entirely representative of hospitals within that region as a whole. Fortunately, there was adequate representation within each of the regions examined, and recruitment efforts (both completed and ongoing) aim to have participation evenly distributed across the country. Finally, this study has examined only process and outcome measures that have been collected during the baseline phase of the On the CUSP: Stop CAUTI intervention. While our cross-sectional analysis provides a snapshot of regional variability in catheter use, appropriateness, and CAUTI rates, temporality cannot be established.

Limitations notwithstanding, we provide baseline estimates of catheter use, appropriateness, and CAUTI rates from more than 1,000 participating units across the United States, revealing some degree of practice and outcome variability by region. Next potential steps include further evaluation of differences in practice between the different regions and identifying learning opportunities from hospitals. Hospitals in areas with lower catheter utilization could be studied as positive deviants to examine how certain characteristics and practices may contribute to minimizing the use of catheters and ultimately CAUTI reduction. Conversely, hospitals in areas with higher catheter utilization could be examined more closely to understand barriers to reducing catheter utilization and CAUTI. Directing enhanced facilitated implementation and coaching of CAUTI prevention strategies to hospitals in areas with higher catheter utilization may help certain hospitals overcome barriers. Furthermore, closer examination of hospital performance within certain geographic areas may help to identify broader organizational and safety culture norms that could be assessed to understand characteristics driving the use of catheters as well as other invasive medical devices. Following the completion of the broadscale implementation of the On the CUSP: Stop CAUTI national initiative, we plan to assess the effect of the intervention on reducing inappropriate catheter use and CAUTI rates. Developing an understanding of any regional variation in the success of the intervention may help to guide and tailor future 
national efforts to prevent CAUTI and other healthcareassociated infections.

\section{ACKNOWLEDGMENTS}

We are indebted to Sarah Krein from the Ann Arbor Veterans Affairs Medical Center and the University of Michigan; Barbara Lucas, Marie Masuga, and Sam Watson from the Michigan Health and Hospital Association; and Barb Edson, Tina Adams, Deborah Bohr, Kelley Faulkner, and Louella Hung from the Health Research and Educational Trust for their help in this collaborative.

Financial support. This project was supported by a contract from the Agency for Healthcare Research and Quality (AHRQ; HHSA290201000025I/ HHSA29032001T).

Potential conflicts of interest. All authors report receiving support for involvement in the On the CUSP: Stop CAUTI initiative. M.G.F. reports receiving support from the Ascension Health Hospital Engagement Network effort to prevent healthcare-associated infections and from the Michigan Health and Hospital Association Hospital Engagement Network to reduce catheter-associated urinary tract infection (CAUTI). J.M. reports being funded by concurrent effort from her AHRQ (K08 HS19767), receiving support for her other research by the AHRQ (2R01HS018334-04) and the National Institutes of Health Loan Repayment Programs, and receiving honoraria from hospitals and specialty societies (eg, Society for Healthcare Epidemiology of America and Association for Professionals in Infection Control and Epidemiology) for educational lectures regarding CAUTI. R.N.O. reports being a consultant for Premier and having served as a member of speakers bureaus for CareFusion, Ethicon, and Sage Products. S.S. reports having received numerous honoraria and speaking fees from academic medical centers, hospitals, group-purchasing organizations (eg, Premier and VHA), specialty societies, state-based hospital associations, and nonprofit foundations (eg, Michigan Health and Hospital Association and Institute for Healthcare Improvement) for lectures about CAUTI, implementing change, and leadership. All authors submitted the ICMJE Form for Disclosure of Potential Conflicts of Interest, and the conflicts that the editors consider relevant to this article are disclosed here.

Address correspondence to $\mathrm{M}$. Todd Greene, $\mathrm{PhD}, \mathrm{MPH}$, Division of General Medicine, University of Michigan, 2800 Plymouth Road, North Campus Research Complex Building 16, Ann Arbor, MI 48109 (mtgreene@med .umich.edu).

\section{REFERENCES}

1. Klevens RM, Edwards JR, Richards CL Jr, et al. Estimating health care-associated infections and deaths in U.S. hospitals, 2002. Public Health Rep 2007;122:160-166.

2. Foxman B. Epidemiology of urinary tract infections: incidence, morbidity, and economic costs. Am J Med 2002;113(suppl 1A): 5S-13S.

3. Saint $S$. Clinical and economic consequences of nosocomial catheter-related bacteriuria. Am J Infect Control 2000;28:68-75.

4. Hollingsworth JM, Rogers MA, Krein SL, et al. Determining the noninfectious complications of indwelling urethral catheters: a systematic review and meta-analysis. Ann Intern Med 2013;159: 401-410.

5. Saint S, Lipsky BA, Baker PD, McDonald LL, Ossenkop K. Urinary catheters: what type do men and their nurses prefer? J Am Geriatr Soc 1999;47:1453-1457.

6. Saint S, Lipsky BA, Goold SD. Indwelling urinary catheters: a one-point restraint? Ann Intern Med 2002;137:125-127.

7. Centers for Medicare and Medicaid Services. Medicare program; changes to the hospital inpatient prospective payment systems and fiscal year 2008 rates. Fed Regist 2007;72:47129-48175.

8. Gould CV, Umscheid CA, Agarwal RK, Kuntz G, Pegues DA; Healthcare Infection Control Practices Advisory Committee. Guideline for prevention of catheter-associated urinary tract infections 2009. Infect Control Hosp Epidemiol 2010;31:319-326.

9. Meddings J, Rogers MA, Krein SL, Fakih MG, Olmsted RN, Saint S. Reducing unnecessary urinary catheter use and other strategies to prevent catheter-associated urinary tract infection: an integrative review. BMJ Qual Saf 2014;23:277-289.

10. Dudeck MA, Horan TC, Peterson KD, et al. National Healthcare Safety Network report, data summary for 2011, device-associated module. Am J Infect Control 2013;41:286-300.

11. Huang WC, Wann SR, Lin SL, et al. Catheter-associated urinary tract infections in intensive care units can be reduced by prompting physicians to remove unnecessary catheters. Infect Control Hosp Epidemiol 2004;25:974-978.

12. Topal J, Conklin S, Camp K, Morris V, Balcezak T, Herbert P. Prevention of nosocomial catheter-associated urinary tract infections through computerized feedback to physicians and a nurse-directed protocol. Am J Med Qual 2005;20:121-126.

13. Saint S, Kaufman SR, Thompson M, Rogers MA, Chenoweth $\mathrm{CE}$. A reminder reduces urinary catheterization in hospitalized patients. Jt Comm J Qual Patient Saf 2005;31:455-462.

14. Crouzet J, Bertrand X, Venier AG, Badoz M, Husson C, Talon $D$. Control of the duration of urinary catheterization: impact on catheter-associated urinary tract infection. J Hosp Infect 2007; 67:253-257.

15. Loeb M, Hunt D, O'Halloran K, Carusone SC, Dafoe N, Walter SD. Stop orders to reduce inappropriate urinary catheterization in hospitalized patients: a randomized controlled trial. $J$ Gen Intern Med 2008;23:816-820.

16. Goetz AM, Kedzuf S, Wagener M, Muder RR. Feedback to nursing staff as an intervention to reduce catheter-associated urinary tract infections. Am J Infect Control 1999;27:402-404.

17. Fakih MG, Dueweke C, Meisner S, et al. Effect of nurse-led multidisciplinary rounds on reducing the unnecessary use of urinary catheterization in hospitalized patients. Infect Control Hosp Epidemiol 2008;29:815-819.

18. Saint S, Kowalski CP, Kaufman SR, et al. Preventing hospitalacquired urinary tract infection in the United States: a national study. Clin Infect Dis 2008;46:243-250.

19. Krein SL, Kowalski CP, Hofer TP, Saint S. Preventing hospitalacquired infections: a national survey of practices reported by U.S. Hospitals in 2005 and 2009. J Gen Intern Med 2012;27: 773-779.

20. Saint S, Greene M, Kowalski C, Watson S, Hofer T, Krein S. Preventing catheter-associated urinary tract infection in the United States: a national comparative study. JAMA Intern Med 2013;173:874-879.

21. Weber DJ, Sickbert-Bennett EE, Gould CV, Brown VM, Huslage $\mathrm{K}$, Rutala WA. Incidence of catheter-associated and non-catheter-associated urinary tract infections in a healthcare system. Infect Control Hosp Epidemiol 2011;32:822-823.

22. Lewis SS, Knelson LP, Moehring RW, Chen LF, Sexton DJ, Anderson DJ. Comparison of non-intensive care unit (ICU) versus ICU rates of catheter-associated urinary tract infection in community hospitals. Infect Control Hosp Epidemiol 2013;34:744747.

23. Wald H, Epstein A, Kramer A. Extended use of indwelling uri- 
nary catheters in postoperative hip fracture patients. Med Care 2005;43:1009-1017.

24. Wald HL, Epstein AM, Radcliff TA, Kramer AM. Extended use of urinary catheters in older surgical patients: a patient safety problem? Infect Control Hosp Epidemiol 2008;29:116-124.

25. Wald HL, Ma A, Bratzler DW, Kramer AM. Indwelling urinary catheter use in the postoperative period: analysis of the national surgical infection prevention project data. Arch Surg 2008;143: 551-557.

26. Rogers MA, Mody L, Kaufman SR, Fries BE, McMahon LF Jr, Saint S. Use of urinary collection devices in skilled nursing facilities in five states. J Am Geriatr Soc 2008;56:854-861.

27. Fakih MG, George C, Edson BS, Goeschel CA, Saint S. Implementing a national program to reduce catheter-associated urinary tract infection: a quality improvement collaboration of state hospital associations, academic medical centers, professional societies, and governmental agencies. Infect Control Hosp Epidemiol 2013;34:1048-1054.

28. Fakih MG, Greene MT, Kennedy EH, et al. Introducing a population-based outcome measure to evaluate the effect of interventions to reduce catheter-associated urinary tract infection. Am J Infect Control 2012;40:359-364.

29. US Census Bureau. Statistical Abstract of the United States. Washington, DC: US Census Bureau, 2012. http://www.census .gov/compendia/statab/. Accessed November 27, 2013.
30. Centers for Disease Control and Prevention (CDC), National Center for Health Statistics. National Hospital Discharge Survey, 2010. Atlanta: CDC, 2010. http://www.cdc.gov/nchs/data/nhds /1general/2010gen1_agesexalos.pdf. Accessed November 28, 2013.

31. Daniels KR, Lee GC, Frei CR. Trends in catheter-associated urinary tract infections among a national cohort of hospitalized adults, 2001-2010. Am J Infect Control 2014;42:17-22.

32. Conway LJ, Pogorzelska M, Larson E, Stone PW. Adoption of policies to prevent catheter-associated urinary tract infections in United States intensive care units. Am J Infect Control 2012; 40:705-710.

33. Centers for Medicare and Medicaid Services. Medicare program; hospital inpatient prospective payment systems for acute care hospitals and the long-term care hospital prospective payment system and FY 2012 rates; hospitals' FTE resident caps for graduate medical education payment. Final rules. Fed Regist 2011; 76:51476-51846.

34. Centers for Medicare and Medicaid Services. Medicare program; hospital inpatient prospective payment systems for acute care hospitals and the long-term care hospital prospective payment system and Fiscal Year 2014 rates; quality reporting requirements for specific providers; hospital conditions of participation; payment policies related to patient status. Final rules. Fed Regist 2013;78:50495-51040. 